\title{
Proteasome inhibition reduces superantigen-mediated $T$ cell activation and the severity of psoriasis in a SCID-hu model
}

\author{
Thomas M. Zollner, ${ }^{1}$ Maurizio Podda, ${ }^{1}$ Christine Pien, ${ }^{2}$ Peter J. Elliott, ${ }^{2}$ \\ Roland Kaufmann, ${ }^{1}$ and Wolf-Henning Boehncke ${ }^{1}$ \\ ${ }^{1}$ Department of Dermatology, J.W. Goethe University of Frankfurt, Frankfurt, Germany \\ ${ }^{2}$ Millennium Pharmaceuticals Inc., Cambridge, Massachusetts, USA \\ Address correspondence to: Thomas M. Zollner, Schering AG, Research Business Unit Dermatology, Müllerstrasse 178, \\ D-13342 Berlin, Germany. Phone: 49-30-468-17235; Fax: 49-30-468-97235; E-mail: Thomas.Zollner@Schering.de.
}

Thomas M. Zollner and Maurizio Podda contributed equally to this work.

Received for publication March 13, 2001, and accepted in revised form January 28, 2002.

\begin{abstract}
There is increasing evidence that bacterial superantigens contribute to inflammation and $T$ cell responses in psoriasis. Psoriatic inflammation entails a complex series of inductive and effector processes that require the regulated expression of various proinflammatory genes, many of which require NF- $\mathrm{\kappa B}$ for maximal trans-activation. PS-519 is a potent and selective proteasome inhibitor based upon the naturally occurring compound lactacystin, which inhibits NF-KB activation by blocking the degradation of its inhibitory protein IKB. We report that proteasome inhibition by PS-519 reduces superantigen-mediated $\mathrm{T}$ cell-activation in vitro and in vivo. Proliferation was inhibited along with the expression of very early (CD69), early (CD25), and late T cell (HLA-DR) activation molecules. Moreover, expression of E-selectin ligands relevant to dermal $\mathrm{T}$ cell homing was reduced, as was E-selectin binding in vitro. Finally, PS-519 proved to be therapeutically effective in a SCID-hu xenogeneic psoriasis transplantation model. We conclude that inhibition of the proteasome, e.g., by PS-519, is a promising means to treat T cell-mediated disorders such as psoriasis.
\end{abstract}

J. Clin. Invest. 109:671-679 (2002). DOI:10.1172/JCI200212736.

\section{Introduction}

Bacterial superantigens are characterized by their ability to interact with and activate $\mathrm{T}$ cells that share defined $\mathrm{T}$ cell receptor $\mathrm{V} \beta$ segments. Therefore, up to $20 \%$ of T cell receptor $\alpha / \beta^{+}$T cells are stimulated by any given superantigen, and this proportion is several orders of magnitude higher than that of activation by conventional antigens (1). Superantigen-mediated T cell activation results in increased proliferation along with secretion of proinflammatory cytokines and upregulated expression of activation markers such as adhesion molecules, including the skin-homing receptor cutaneous lymphocyte-associated antigen (CLA) $(2-4)$. There is increasing evidence that superantigens are involved in the pathogenesis of several autoimmune diseases, e.g., rheumatoid arthritis and diabetes mellitus $(5,6)$. Another T cell-mediated autoimmune disease is psoriasis. Clinically, there is an association of this disease with bacterial infections, as colonization and infection with Staphylococcus and Streptococcus have been reported to exacerbate psoriasis $(7,8)$. In this regard, Staphylococcus aureus has been found on the skin of more than half of the patients with chronic plaque psoriasis, and more than half of the clinically isolated strains produce superantigens $(8,9)$. Exacerbation of chronic plaque psoriasis by superantigens has been observed (9), although the most convincing clinical association between bacterial infection and psoriasis is in patients with acute guttate psoriasis. The observation that streptococcal $\mathrm{M}$ proteins and keratins share common epitopes led to the hypothesis of psoriasis being triggered by superantigen-activated T cells crossreacting with keratins $(10,11)$.

Induction of psoriasis has been demonstrated experimentally in the SCID-hu xenogeneic transplantation model by injecting bacterial superantigens into nonlesional psoriatic skin transplanted onto mice lacking functional $\mathrm{B}$ and $\mathrm{T}$ cells (12). This phenomenon was found to be $\mathrm{T}$ cell-dependent $(13,14)$. Lesional $\mathrm{T}$ cells are characterized by the expression of numerous activation markers such as the very-early-appearing CD69 (15), early IL-2 receptor $\alpha$-chain CD25, the laterappearing HLA-DR (16), and adhesion molecules such as CLA and CD15s (17-19). Regulation of these molecules involves NF- $\mathrm{KB}(20)$.

The major intracellular pathway for protein degradation is the ubiquitin-proteasome pathway (UPP) (21, 22). The proteasome is a large multimeric protease present in all eukaryotic cells that exhibits a highly conserved so-called $20 \mathrm{~S}$ core structure (23). Proteasomes are responsible for the degradation of protein substrates after they have been "tagged" by a poly-ubiquitin chain (24). The inflammatory events in psoriasis are composed of a complex series of inductive and effector 
processes, which require the regulated expression of various proinflammatory genes. NF- $\kappa \mathrm{B}$ is a protein transcription factor that is required for maximal transcription of many of these proinflammatory molecules (25). It consists of a heterodimer of the $\mathrm{p} 50$ and $\mathrm{p} 65$ proteins retained inactive in the cytoplasm tightly bound to the inhibitory subunit I $\mathrm{I} B \alpha$. Upon activation, I $\mathrm{I} B \alpha$ is rapidly and sequentially phosphorylated by the action of I $\mathrm{KB}$ kinases (IKKs), ubiquitinated, and degraded by the UPP (26). The active subunit (p50 and p65) is translocated to the nucleus, where it binds to cognate DNA sequences and stimulates gene transcription. Effective inhibition of proteasome-mediated IKB degradation can therefore limit inflammatory events via the attenuation of NF-KB-promoted expression of multiple inflammatory mediators (27).

PS-519 is a potent and selective proteasome inhibitor based upon the naturally occurring compound lactacystin (28). This proteasome inhibitor selectively affects the chymotryptic activity of the $20 \mathrm{~S}$ proteasome with limited activity on other enzymes including serine and threonine proteases (P.J. Elliott, unpublished observations). Partial and temporal inhibition of the proteasome, by PS-519, leads to profound effects on numerous intracellular proteins. Many of these proteins affect the inflammatory cascade and include the inhibitory

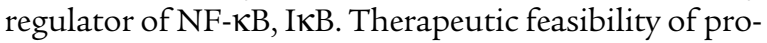
teasome inhibition has been demonstrated in animal models of inflammation including rheumatoid arthritis, asthma, and multiple sclerosis (29-31). Interestingly, glucocorticosteroids are also known to interfere with NF-KB activity. Specifically, these steroids induce the transcription of the IKB gene, leading to the production of IKB protein. This newly synthesized protein can then bind free NF- $\mathrm{KB}$ molecules, thereby limiting their proinflammatory activity $(32,33)$. It is possible that steroids are active in treating psoriasis because of this additional intracellular effect. However, other well-established effects of steroids in this inflammatory condition, namely suppression of several proinflammatory transcription factors through glucocorticoid receptor activation, clearly play a role in steroid activity $(34,35)$.

We here report the capability of the proteasome inhibitor PS-519 to reduce superantigen-mediated T cell activation. Proliferation was inhibited along with the expression of very early, early, and late $T$ cell activation molecules. Moreover, expression of E-selectin ligands relevant for $\mathrm{T}$ cell homing to the skin was reduced, and so was the binding to E-selectin in vitro. These data suggest that PS-519 is an effective agent in a SCID-hu xenogeneic transplantation model and may have therapeutic utility in psoriasis.

\section{Methods}

Cell source and preparation. Peripheral blood was drawn from healthy adult donors after informed consent. PBMCs were prepared by density gradient sedimentation (Histopaque 1077; Sigma-Aldrich Co., St. Louis, Missouri, USA). Negative isolation of highly purified $\mathrm{T}$ cells was performed using magnetic cell separation according to standard procedures using the Pan T cell Isolation Kit (Miltenyi Biotec GmbH, Bergisch Gladbach, Germany). Selected cells were $\geq 97 \% \mathrm{CD}^{+}$. PBMCs or highly purified $\mathrm{T}$ cells were cultured in AIM-V medium (Life Technologies Inc., Grand Island, New York, USA) supplemented with 5\% FCS (Life Technologies Inc.). Phytohemagglutinin (Biochrom AG, Berlin, Germany) $(1 \mu \mathrm{g} / \mathrm{ml}), N$-acetylcysteine $(25 \mathrm{mM})$, and toxic shock syndrome toxin-1 (TSST-1) $(100 \mathrm{ng} / \mathrm{ml})$ were obtained from SigmaAldrich Co., and TGF- $\beta(50 \mathrm{ng} / \mathrm{ml})$ from R\&D Systems Inc. (Minneapolis, Minnesota, USA). IL-2 (100 $\mathrm{U} / \mathrm{ml}$ ) was a kind gift of Chiron Behring $\mathrm{GmbH}$ and Co. (Marburg, Germany). PS-519 was produced by Millennium Pharmaceuticals Inc. (28).

Monoclonal antibodies were purchased from BD Biosciences (Heidelberg, Germany) (CD3, HLA-DR, CLA, CD15s) or Immunotech GmbH (Hamburg, Germany) (CD25, CD69). Recombinant human E- and P-selectin IgG fusion proteins were obtained from R\&D Systems Inc. and BD Biosciences, respectively.

Electrophoretic mobility shift assay. Total cell extracts from $5 \times 10^{6}$ to $1 \times 10^{7}$ PBMCs or T cells were prepared by resuspending PBS-washed cell pellets with a buffer containing the detergent Igepal CA-630 (SigmaAldrich Co.), as described previously (36). Protein concentrations of supernatants were determined by Biorad detergent compatible assay (Bio-Rad Laboratories, Hercules, California, USA). DNA-binding conditions for NF-KB have been described in detail previously (37). Briefly, $10 \mu \mathrm{g}$ of protein was used for binding reaction, which contained $10,000 \mathrm{cpm}$ of ${ }^{32} \mathrm{P}$-labeled, double-stranded oligonucleotide with a high-affinity

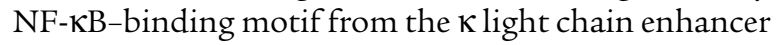
(Promega Corp., Madison, Wisconsin, USA). DNAbinding reactions were analyzed by electrophoresis on native $4 \%$ polyacrylamide gels. Dried gels were exposed to Kodak XR films (Eastman Kodak Co., Rochester, New York, USA). The radioactivity in the NF-kB DNA complexes was quantitated by scanning and NIH Image analysis (Scion Image for Windows; Scion Corp., Frederick, Maryland, USA).

Proliferation analysis. PBMCs $\left(2 \times 10^{6} / \mathrm{ml}\right)$ were stimulated with TSST-1 $(100 \mathrm{ng} / \mathrm{ml})$ in 96-well flat-bottom microplates in AIM-V medium supplemented with 5\% FCS for 4 days in the presence or absence of PS-519 $(0-5 \mu \mathrm{g} / \mathrm{ml})$ or vehicle (propylene glycol/ $0.9 \%$ saline [1:1]). At the culture initiation, PS-519 was added 1 hour prior to TSST-1 and supplemented daily. After 4 days at $37^{\circ} \mathrm{C}$ in $5 \% \mathrm{CO}_{2} /$ air, cells were labeled for 18 hours with $0.5 \mu \mathrm{Ci}{ }^{3} \mathrm{H}$-thymidine (NEN Life Science Products Inc., Boston, Massachusetts, USA), and proliferative response was determined using a liquid scintillation counter. Control experiments were performed with vehicle only (propylene glycol/0.9\% saline [1:1]) and showed no change in ${ }^{3} \mathrm{H}$-thymidine uptake.

Phenotype analysis. Freshly isolated PBMCs $\left(1 \times 10^{6} / \mathrm{ml}\right)$ were stimulated for $1-7$ days with TSST-1 $(100 \mathrm{ng} / \mathrm{ml})$ 
in the presence or absence of PS-519 $(0.25-2.5 \mu \mathrm{g} / \mathrm{ml})$. PS-519 was added 1 hour before culture initiation and supplemented daily. Control experiments were performed with vehicle only (propylene glycol/0.9\% saline [1:1]) and showed no change in the expression of the analyzed surface markers. Staining was performed at the indicated time points by standard direct or indirect immunofluorescence labeling techniques with goatanti-rat IgM-F(ab) $)_{2}$-phycoerythrin. In each sample, irrelevant mAb's of the appropriate isotype were used as controls. Fluorocytometer analysis was performed on a FACSCalibur (BD Biosciences) using standard procedures with CellQuest research software (BD Biosciences). Lymphocytes were detected in a gate set on lymphocyte-sized cells.

In vitro E-selectin and $P$-selectin binding assay. Recombinant human E- and P-selectin IgG fusion proteins were obtained from R\&D Systems Inc. and from PharMingen (Hamburg, Germany), respectively. We incubated $5 \times 10^{5}$ $\mathrm{T}$ cells for 30 minutes with $1 \mu \mathrm{g}$ fusion protein in $\mathrm{Ca}^{++} / \mathrm{Mg}^{++}$containing PBS at room temperature. Thereafter, cells were washed, labeled with anti-human IgGphycoerythrin (Dianova GmbH, Hamburg, Germany) for 15 minutes, and analyzed on a FACSCalibur using the CellQuest software (BD Biosciences) as outlined above. Staining in the absence of fusion proteins and in the presence of anti-CD3-FITC together with secondary anti-human IgG-phycoerythrin demonstrated absence of unspecific binding reactivity.

Skin donors. This study was approved by the ethics committee of the faculty of medicine of the Johann Wolfgang Goethe-University Frankfurt. Written informed consent was obtained from patients with chronic plaque-stage psoriasis, and lesional skin was excised from the upper arm in local anesthesia.

Transplantation procedure. The animal experiments were approved by the Regierungspraesidium Darmstadt. Transplantations were done as described previously $(38,39)$. Human full-thickness xenografts were transplanted onto the backs of 6- to 8-week-old C.B17 SCID mice (Charles River Deutschland GmbH, Sulzfeld, Germany). For the surgical procedure, mice were anesthetized by intraperitoneal injection of 100 $\mathrm{mg} / \mathrm{kg}$ ketamine and $5 \mathrm{mg} / \mathrm{kg}$ xylazine. Spindle-shaped pieces of full-thickness skin measuring $1 \mathrm{~cm}$ in diameter were grafted onto corresponding excisional fullthickness defects of the shaved central dorsum of the mice and fixed by 6-0 atraumatic monofilament sutures. After applying a sterile Vaseline-impregnated gauze, the grafts were protected from injury by suturing a skin pouch over the transplanted area using the adjacent lateral skin. The sutures and over-tied pouches were left in place until they resolved spontaneously after 2-3 weeks.

Treatment protocol. Grafts were allowed 2 weeks for acceptance and healing. Thereafter, daily intraperitoneal injections were performed between days 15 and 42 after transplantation. Mice received either vehicle (propylene glycol/0.9\% saline [1:1]), dexamethasone
$(0.2 \mathrm{mg} / \mathrm{kg}$ body weight), or PS-519 (1 mg/ $\mathrm{kg}$ body weight) in a final volume of $200 \mu$ l. The grafts of each of the donors underwent an identical treatment protocol. The data on histological analysis of the skin sections are based on findings of 12 different grafts from four psoriasis patients (four control, four PS-519-treated, and four dexamethasone-treated animals), whereas data on 20 s proteasome activity are based on 16 different grafts (four control, four dexamethasone-treated, and eight PS-519-treated animals).

Histological analysis of the grafts. Mice were sacrificed at day 42 , and after excision with surrounding mouse skin the grafts were formalin-embedded. Subsequently, routine hematoxylin-and-eosin stainings were performed, and the grafts were analyzed with regard to their pathological changes both qualitatively (epidermal differentiation, inflammatory infiltrate) and quantitatively (epidermal thickness) by a blinded investigator as described previously $(38,39)$. Briefly, maximal epidermal thickness was measured from the tip of the rete ridges to the border of the viable epidermis. The values were determined using an ocular micrometer, taking the mean of ten consecutively measured rete ridges. The number of infiltrating leukocytes was evaluated by counting stained leukocytes in five adjacent high-power fields. For immunohistochemical analysis, skin samples were immediately snap-frozen in liquid nitrogen and stainings were performed as described previously (38).

Assay of 20 S proteasome activity. Inhibition of $20 \mathrm{~S}$ proteasome activity was measured in blood samples. Blood $(500 \mu \mathrm{l})$ was collected in sodium heparin-containing tubes and centrifuged at $2200 \mathrm{~g}$ for 10 minutes at $4{ }^{\circ} \mathrm{C}$. Plasma was discarded and the pellet washed with cold $1 \times$ PBS. The blood cells were lysed with 5 mM EDTA ( $\mathrm{pH}$ 8.0) for 1 hour and then centrifuged at $6600 \mathrm{~g}$ for 10 minutes at $4^{\circ} \mathrm{C}$. The whole-blood lysate samples were then used in the $20 \mathrm{~S}$ proteasome assay as previously described (40). Briefly, samples $(10 \mu \mathrm{l})$ were added to $2 \mathrm{ml}$ of substrate buffer (20 mM HEPES, 0.5 mM EDTA, $0.05 \%$ SDS, and $60 \mathrm{mM}$ Ys substrate SucLeu-Leu-Val-Tyr-AMC [Bachem Biochemica GmbH, Heidelberg, Germany]). The reaction was carried out at $37^{\circ} \mathrm{C}$ for 5 minutes, and the rate of substrate cleavage per $20 \mathrm{~S}$ proteasome activity was determined. The protein content of the samples was determined using a Coomassie protein assay (Pierce Chemical Co., Rockford, Illinois, USA).

Statistical analysis. Data are presented as mean \pm SD. All data satisfied the normality test and were analyzed by either one-way ANOVA with Dunnett's multiple comparison post-test or Student $t$ test using InStat version 3.00 for Windows 95 (GraphPad Software for Science Inc., San Diego, California, USA). $P$ values less than 0.05 were considered statistically significant.

\section{Results}

$T$ cell activation-induced NF- $K B$ DNA binding in buman $T$ cells is suppressed by the proteasome inhibitor PS-519. Since activated $\mathrm{T}$ cells are involved in maintaining psoriatic 


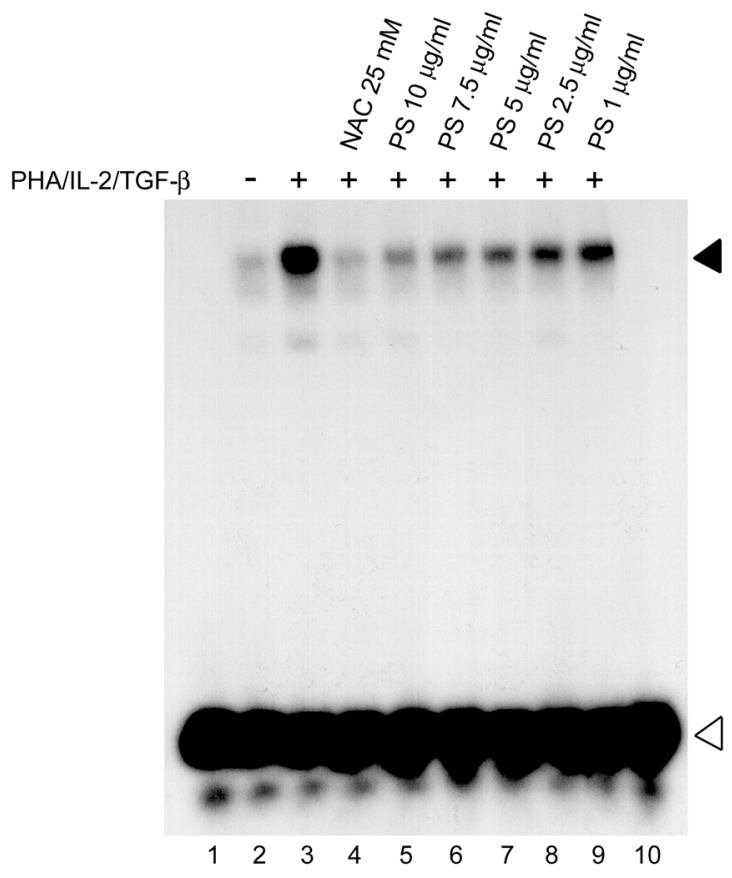

skin lesions and many $\mathrm{T}$ cell activating signals are transduced via activation of the nuclear transcription factor $\kappa \mathrm{B}$, we assessed the effects of PS-519 on superantigen- and cytokine-stimulated cells. PBMCs were stimulated with TSST-1 $(100 \mathrm{ng} / \mathrm{ml})$, and highly purified human $\mathrm{T}$ cells were stimulated with PHA (1 $\mu \mathrm{g} / \mathrm{ml})$, IL-2 $(100 \mathrm{U} / \mathrm{ml})$, and TGF- $\beta(50 \mathrm{ng} / \mathrm{ml})$. Total cell extracts were isolated 4 hours after culture initiation as outlined in Methods and analyzed for NF- $\mathrm{KB}$-binding activity using a ${ }^{32}$ P-labeled oligonucleotide probe. As we reported earlier, we found, in a time-dependent manner, the appearance of a proteinDNA complex, which was first observable after $30 \mathrm{~min}-$ utes and reached a maximum after 4 hours (41). The PHA/IL-2/TGF- $\beta$-induced protein-DNA complex was characterized by using subunit-specific antibodies against p50 and p65 subunits of NF- $\kappa B$. These subunits form prototypic heterodimers that are most frequently observed upon stimulation of various cell types with diverse conditions. Almost all of the proteinDNA complex newly induced by PHA/IL-2/TGF- $\beta$ treatment was supershifted upon the addition of spe-

\section{Figure 2}

PS-519 inhibits TSST-1-induced T cell proliferation. PBMCs $\left(2 \times 10^{6} / \mathrm{ml}\right)$ obtained from five healthy volunteers were stimulated with TSST-1 $(100 \mathrm{ng} / \mathrm{ml})$ in the absence or presence of PS-519 $(0.25-2.5 \mu \mathrm{g} / \mathrm{ml})$ for 4 days and thereafter pulsed with ${ }^{3} \mathrm{H}$-thymidine. Incorporation of ${ }^{3} \mathrm{H}$-thymidine into DNA was calculated using a liquid scintillation counter. Stimulation index was calculated by the ratio: decays per minute of experimental group/decays per minute of control group. Open symbols represent resting PBMCs, filled symbols TSST-1-stimulated PBMCs. A significant reduction in proliferation was observed starting at $0.25 \mu \mathrm{g} / \mathrm{ml} \mathrm{PS}-519$ $\left({ }^{*} P<0.001\right)$. Values represent mean $\pm \mathrm{SD}$ of five healthy donors.

\section{Figure 1}

The PHA/IL-2/TGF- $\beta$-induced NF-KB DNA complex is suppressed by the proteasome inhibitor PS-519. Human T cells were stimulated with PHA/IL-2/TGF- $\beta$ for 4 hours. PS-519 $(1-10 \mu \mathrm{g} / \mathrm{ml})$ suppressed NF- $\kappa B$ DNA-binding activity. The NF- $\kappa B$ DNA complex is indicated by a filled arrowhead. The open arrowhead shows the position of the unbound DNA probe. Binding mixture without cell extract was applied on lanes 1 and 10 . The antioxidant $N$-acetylcysteine (NAC; $25 \mathrm{mM}$ ), which is known to inhibit IKB kinase, served as control (lane 4). The results are representative of three electrophoretic mobility shift assays from three independent donors.

cific antibodies against the p50 and p65 subunits of $\mathrm{NF}-\kappa \mathrm{B}$ to the DNA-binding reaction. A nonspecific antibody was ineffective (41). This suggests that PHA/IL-2/TGF- $\beta$ treatment induced complexes predominantly containing p50 and p65 subunits.

The appearance of the NF- $\kappa \mathrm{B}$ DNA-binding complex was reduced in a dose-dependent manner using PS-519. $\mathrm{T}$ cells or PBMCs were pretreated for 1 hour with PS-519 $(1-10 \mu \mathrm{g} / \mathrm{ml})$. Thereafter, cells were stimulated with PHA/IL-2/TGF- $\beta$ or TSST- 1 for 4 hours. As expected, PS-519 suppressed NF-kB DNA-binding activity in stimulated $T$ cells and PBMCs (Figure 1).

PS-519 inbibits TSST-1-induced T cell proliferation. Superantigens such as TSST-1 belong to the strongest T cell-activating compounds because they stimulate a large proportion of $\mathrm{T}$ cells, as compared with nominal antigens, via their interaction with the $T$ cell receptor $\mathrm{V} \beta$-chain. Additionally, they have been shown to be involved in the induction of psoriasis in animal models of the disease and in human studies $(12,13,42,43)$. Therefore, we analyzed the effects of PS-519 on T cell proliferation and activation in superantigen-stimulated cells. TSST- 1 induced a 28 -fold increase in ${ }^{3} \mathrm{H}$-thymidine incorporation, which was inhibited in a dosedependent manner by PS-519 and reached a maximum at $2.5 \mu \mathrm{g} / \mathrm{ml}$. Stimulation indexes were: unstimulated cells, 1 ; TSST-1-stimulated cells, $28.13 \pm 3.30$; cells stimulated with TSST- 1 and PS- $519(2.5 \mu \mathrm{g} / \mathrm{ml}), 1.65 \pm 1.81$ (Figure 2). Proliferation of unstimulated cells cultured in the presence of PS-519 $(0.25-2.5 \mu \mathrm{g} / \mathrm{ml})$ remained unchanged (Figure 2). Using trypan blue exclusion tests and propidium iodide uptake, we excluded toxic effects of PS-519 as a possible cause for reduced T cell proliferation (data not shown).

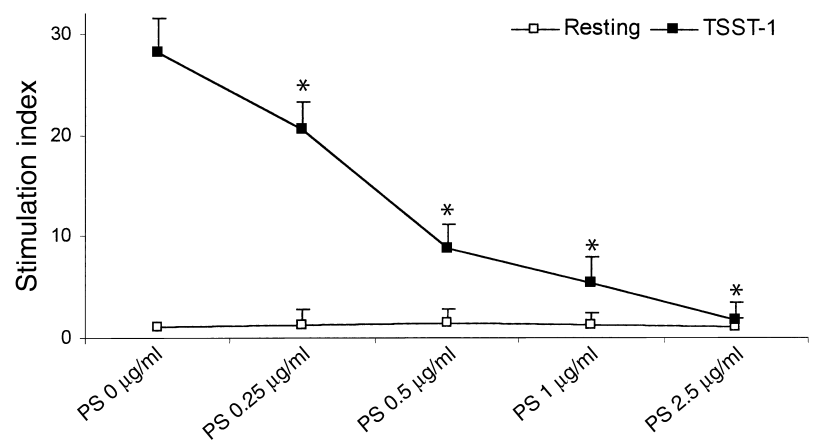


a

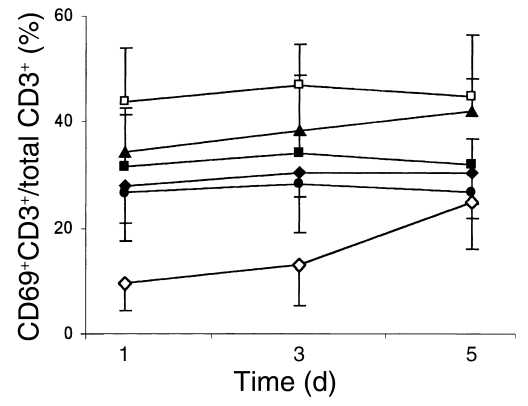

$\multimap$ Unstimulated

$\rightarrow-$ TSST-1 b

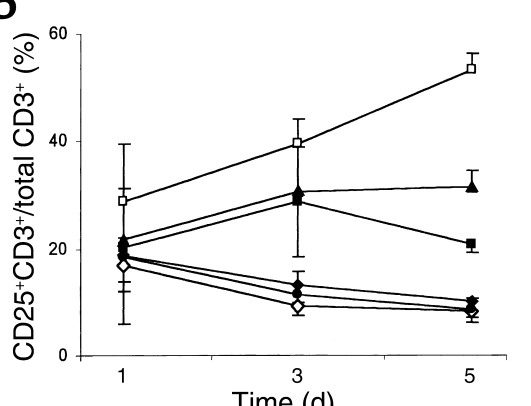

Time (d)
C

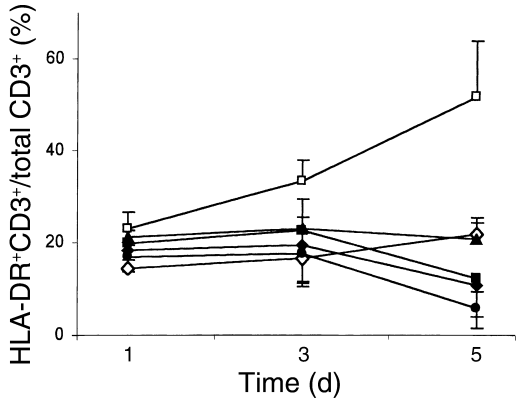

$\begin{aligned} & \longrightarrow \text { PS } 0.25 \mu \mathrm{g} / \mathrm{ml} \\ & \longrightarrow \text { PS } 0.5 \mu \mathrm{g} / \mathrm{ml}\end{aligned} \mid+$ TSST-1 \begin{tabular}{l|l}
$\longrightarrow$ PS $1.0 \mu \mathrm{g} / \mathrm{ml}$ & + TSST-1
\end{tabular}

Figure 3

PS-519 inhibits TSST-1-induced expression of T cell activation molecules. PBMCs were stimulated with TSST-1 (100 $\mathrm{ng} / \mathrm{ml})$ in the presence or

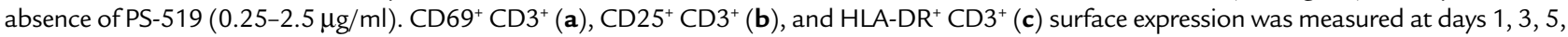
7 , and 9 (days 7 and 9 not shown) by flow cytometry. Appropriate isotype lg's served as controls to set gates for positive and negative staining. For CD69 expression, significant reduction was observed on day 1 starting at $1.0 \mu \mathrm{g} / \mathrm{ml}(P<0.05)$, and on days 3 and 5 starting at $0.5 \mu \mathrm{g} / \mathrm{ml} \mathrm{PS}-519$ $(P<0.001$ and $P<0.05$, respectively). For CD25 expression, significant reduction was observed on day 3 starting at $1.0 \mu \mathrm{g} / \mathrm{ml}(P<0.001)$, and on day 5 starting at $0.25 \mu \mathrm{g} / \mathrm{ml} \mathrm{PS}-519(P<0.001)$. For HLA-DR expression, significant reduction was observed on day $1 \mathrm{at} 2.5 \mu \mathrm{g} / \mathrm{ml}(P<0.05)$, on day 3 starting at $1.0 \mu \mathrm{g} / \mathrm{ml}(P<0.05)$, and on day 5 starting at $0.25 \mu \mathrm{g} / \mathrm{ml} \mathrm{PS}-519(P<0.001)$. Data represent means of five experiments \pm SD.

PS-519 inbibits TSST-1-induced expression of T cell activation molecules. Since superantigens are potent activators of $\mathrm{T}$ cells and activated $\mathrm{T}$ cells are involved in maintaining the psoriatic skin lesions, we investigated the effects of the proteasome inhibitor PS-519 on superantigen-mediated $\mathrm{T}$ cell activation. For this purpose we chose the very early activation marker CD69, the early activation marker $\mathrm{CD} 25$, and the late activation marker HLA-DR, which are all under the transcriptional control of NF- $\mathrm{KB}(15,25,44,45)$. In TSST-1-stimulated cells, CD69 expression increased about fourfold at day 1 (unstimulated cells $9.62 \% \pm 5.24 \%$ versus TSST- 1 stimulated cells $43.89 \% \pm 10.14 \%$ ) and remained unchanged for 5 days. PS-519 significantly and dosedependently reduced CD69 expression by T cells up to 40\% (Figure 3a). CD25 expression by $\mathrm{T}$ cells continuously increased, reaching a plateau at day 5 of TSST-1 stimulation (day 5: unstimulated cells $8.32 \% \pm 2.29 \%$ versus TSST-1-stimulated cells $53.34 \% \pm 2.99 \%)$ and remained stable until day 9 (data not shown). Again, PS-519 induced a dose-dependent inhibition of this activation marker with a complete suppression of

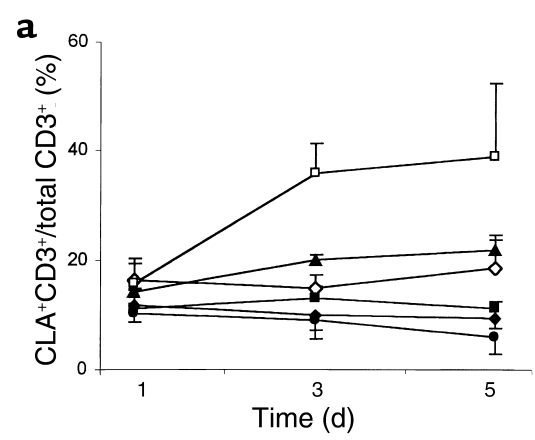

$\rightarrow$ Unstimulated
$\rightarrow \square$ TSST-1 b
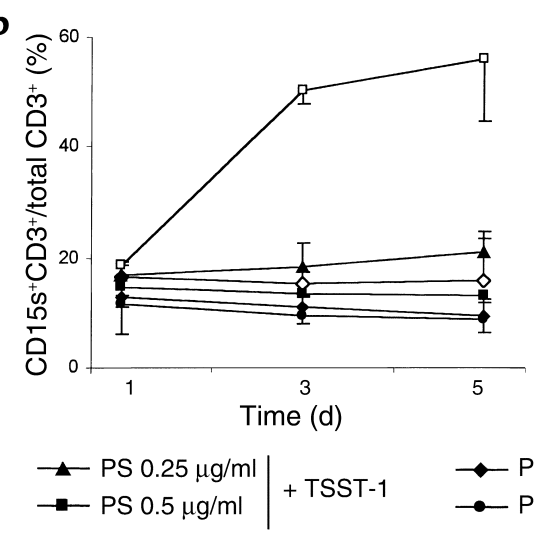

c

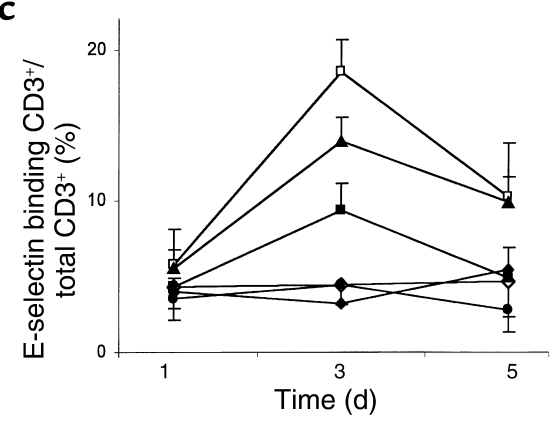

+ TSST-1

\section{Figure 4}

PS-519 inhibits TSST-1-induced expression of T cell adhesion molecules. PBMCs were stimulated with TSST-1 (100 ng/ml) in the presence or absence of PS-519 $(0.25-2.5 \mu \mathrm{g} / \mathrm{ml})$. CLA ${ }^{+} \mathrm{CD}^{+}(\mathbf{a})$ and $\mathrm{CD} 15 \mathrm{~s}^{+} \mathrm{CD}^{+}(\mathbf{b})$ surface expression and binding of CD3 ${ }^{+}$cells to E-selectin $(\mathbf{c})$ was measured at days 1, 3, 5, 7, and 9 (days 1 and 9 not shown) by flow cytometry. Appropriate isotype Ig's served as controls to set gates for positive and negative staining. Staining in the absence of fusion proteins and in the presence of anti-CD3-FITC together with secondary anti-human IgG-phycoerythrin demonstrated absence of unspecific binding reactivity. For CLA expression, significant reduction was observed on day 3 at $2.5 \mu \mathrm{g} / \mathrm{ml}(P<0.05)$, and on days 5 and 7 starting at $0.25 \mu \mathrm{g} / \mathrm{ml} \mathrm{PS}-519(P<0.001)$. For CD15s expression, significant reduction was observed on days 5 and 7 starting at $0.25 \mu \mathrm{g} / \mathrm{ml} \mathrm{PS}-519(P<0.001)$. For E-selectin binding, significant reduction was observed on day 5 starting at 0.25 $\mu \mathrm{g} / \mathrm{ml}(P<0.001)$, and on day 7 starting at $0.5 \mu \mathrm{g} / \mathrm{ml} \mathrm{PS}-519(P<0.05)$. Data represent means of five independent experiments \pm SD. 

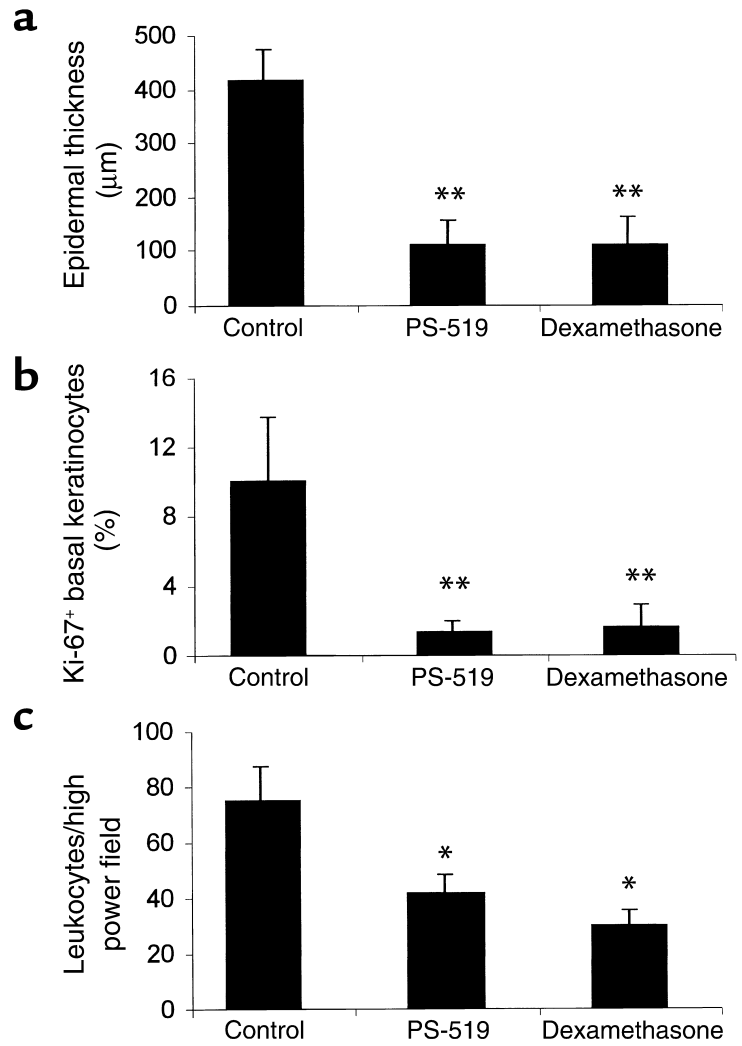

\section{Figure 5}

PS-519 suppresses hallmarks of psoriasis in a xenogeneic transplantation model. Grafts from lesional psoriatic skin were transplanted onto SCID mice as outlined in Methods. After 2 weeks, mice were treated with PS-519 (1 mg/kg body weight), dexamethasone $(0.2 \mathrm{mg} / \mathrm{kg}$ body weight), or vehicle for 4 weeks. Subsequently, epidermal thickness (a), proliferation of basal keratinocytes measured by $\mathrm{Ki}-67$ reactivity $(\mathbf{b})$, and leukocytic infiltration $(\mathbf{c})$ were determined by a blinded investigator. All parameters showed a marked reduction $\left({ }^{*} P<0.05,{ }^{*} P<0.001\right)$. Data represent means of four independent experiments \pm SD

CD25 upregulation at $2.5 \mu \mathrm{g} / \mathrm{ml}$ (Figure $3 \mathrm{~b}$ ). HLA-DR expression by TSST-1-stimulated T cells peaked at day 5 (unstimulated cells $21.79 \% \pm 3.41 \%$ versus TSST- 1 stimulated cells $51.79 \% \pm 12.26 \%$ ) with a decline at day 9 (data not shown). HLA-DR expression by $\mathrm{T}$ cells treated in the presence of PS-519 was significantly reduced even as compared with unstimulated cells $(5.81 \% \pm 4.40 \% ; P<0.01$; Figure $3 c)$.

PS-519 inhibits TSST-1-induced expression of T cell homing molecules. Recirculation of activated $\mathrm{T}$ cells into the skin is of key importance for both immunosurveillance and $\mathrm{T}$ cell-mediated inflammatory disorders such as psoriasis. We therefore examined the effects of PS-519 on TSST-1-induced upregulation of molecules known to be expressed by skin-seeking $T$ cells. Expression of CLA and the closely related moiety sialyl Lewis ${ }^{\mathrm{X}}\left(\mathrm{sLe}^{\mathrm{X}}=\mathrm{CD} 15 \mathrm{~s}\right)$ is induced by superantigens $(2-4,46)$. As described, we observed a maximum induction of both antigens at day 5 of TSST-1 stimulation (CLA: control cells $14.57 \% \pm 2.52 \%$ versus
TSST-1-stimulated cells $35.67 \% \pm 5.63 \%$; CD 15 s: control cells $15.31 \% \pm 1.99 \%$ versus TSST- 1 -stimulated cells $50.19 \% \pm 2.51 \%)$. In PS-519-treated cells, the TSST-1-induced upregulation of both skin-homing molecules was completely inhibited in a dosedependent manner, and, even in concentrations as low as $0.5 \mu \mathrm{g} / \mathrm{ml}$, CLA and CD15s expression remained below control levels (CLA: PS-519-treated $[2.5 \mu \mathrm{g} / \mathrm{ml}]$ and TSST-1-treated cells $9.61 \% \pm 1.72 \%$; CD15s: $9.61 \% \pm 1.72 \%$; Figure 4 , a and b). CLA and CD15s expression correlated with in vitro E-selectin binding, which was also completely inhibited by PS-519 treatment in concentrations above $1 \mu \mathrm{g} / \mathrm{ml}$ (Figure 4c). In vitro binding of $\mathrm{T}$ cells to P-selectin remained unchanged in TSST-1- and TSST-1+PS-519treated cells as compared with control cells (data not shown). CD54 expression was also inhibited by PS-519, but to a lesser extent as compared with suppression of CLA or CD15s (data not shown).

Interestingly, lower concentrations of PS-519 were necessary for inhibition of $\mathrm{T}$ cell proliferation, of $\mathrm{T}$ cell activation markers, and of cell adhesion molecules as compared with inhibition of NF-KB DNA binding (Figures 1-4). This can be explained by the fact that threshold levels of active NF- $\mathrm{\kappa B}$ are required for T cell activation and optimal cellular adhesion molecule expression. Therefore, a small decrease in the level of activated NF- $\kappa \mathrm{B}$ can lead to a profound change in the level of transcription $(27,30)$.

PS-519 is effective in the treatment of psoriasis in a xenogeneic transplantation model. Having demonstrated reduced superantigen-mediated $\mathrm{T}$ cell activation in vitro, we employed PS-519 as a therapeutic tool in a SCID-hu xenogeneic transplantation model that proved to be a useful tool in the evaluation of antipsoriatic drugs $(47,48)$. Only grafts from lesional psoriatic skin treated with the vehicle retained their increased epidermal thickness ( $414 \pm 54 \mu \mathrm{m}$; Figures $5 \mathrm{a}$ and 6$)$ and papillomatosis. The percentage of proliferating basal keratinocytes expressing the proliferation marker Ki-67 was $10 \% \pm 4 \%$ (Figures $5 \mathrm{~b}$ and 6 ). A dense leukocytic infiltrate was present in the upper dermis (75 \pm 12 leukocytes per high power field; Figure $5 c$ ). In contrast, grafts treated with PS-519 exhibited a markedly reduced epidermal thickness $(110 \pm 43 \mu \mathrm{m})$ along with fewer Ki-67-positive basal keratinocytes $(1 \% \pm 1 \%)$. The remaining inflammatory infiltrate localized in the upper dermis was reduced (41 \pm 7 leukocytes per high power field; Figure 5 , a-c). These changes paralleled the findings in grafts of mice that received dexamethasone treatment (Figure 5, a-c, and Figure 6).

$20 S$ proteasome activity is reduced in PS-519-treated animals. To determine the pharmacodynamics of PS-519 from these transplanted mice, blood was collected 2 hours after treatment at days $4,8,14$, and 28 from PS-519- and vehicle-treated animals. Results indicate an $85.7 \% \pm 8.6 \%$ (mean $\pm \mathrm{SD}$ ) reduction in proteasome activity in the PS-519-treated animals as compared with the control (Figure 7). Already after 4 days of treatment, 


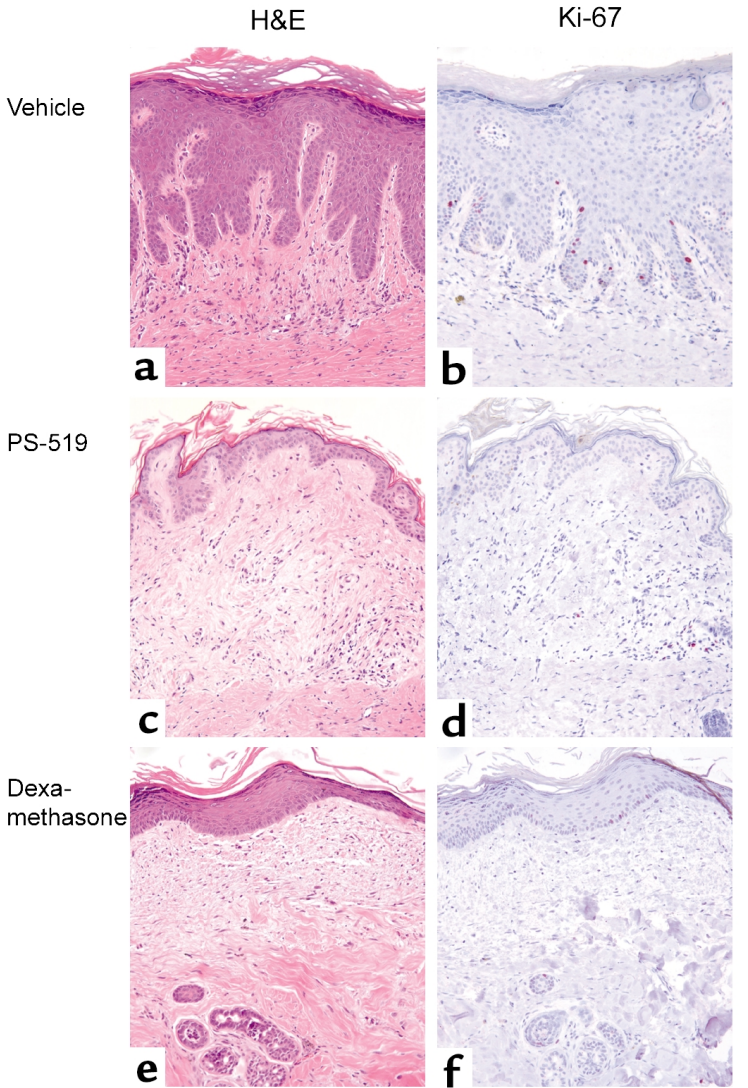

20 S proteasome activity was reduced by $81.6 \% \pm 1.7 \%$, indicating that the effects were achieved quite early after the beginning of treatment. In the vehicle-treated mice, $20 \mathrm{~S}$ proteasome activity remained constant during the whole experimental period (data not shown). No effect on $20 \mathrm{~S}$ proteasome activity was seen in the dexamethasone-treated group (data not shown). These data support the critical role the proteasome plays to suppress the activation of NF- $\mathrm{KB}$, thereby decreasing the transcription of many genes encoding proinflammatory proteins, including the $\mathrm{T}$ cell surface markers.

\section{Discussion}

Our results demonstrate that the selective proteasome inhibitor PS-519 can significantly inhibit numerous parameters in the process of superantigenmediated $\mathrm{T}$ cell activation in vitro and act as a potent therapeutic agent for psoriasis in a xenogeneic transplantation model.

The relevance of superantigen-mediated $\mathrm{T}$ cell activation in the triggering process of psoriasis is documented by findings of numerous research groups and is thought to be greater for patients suffering from acute guttate psoriasis than for those with chronic plaque-stage psoriasis $(9,10,12,13,43)$. Moreover, activated T cells are involved in maintaining the psoriatic skin lesions $(49,50)$. This is underscored by the observation that injection of IL-2 and superantigen-stimulated $\mathrm{T}$ lymphocytes into SCIDhu mice is sufficient to induce a full-fledged psoriat-

\section{Figure 6}

PS-519 suppresses hallmarks of psoriasis in a xenogeneic transplantation model. Grafted skin in PS-519-treated mice $(1 \mathrm{mg} / \mathrm{kg}$ body weight) showed normalization of epidermal architecture, loss of papillomatosis, and marked reduction of acanthosis (c, hematoxylin-andeosin stain) as compared with vehicle-treated mice (a, hematoxylinand-eosin stain). In PS-519-treated (d, Ki-67 stain) as compared with vehicle-treated mice (b, Ki-67 stain), proliferation of basal keratinocytes was markedly reduced. Treatment with dexamethasone $(0.2$ $\mathrm{mg} / \mathrm{kg}$ body weight; $\mathbf{e}$ and $\mathbf{f}$ ) was as effective as PS-519 treatment. The sections show one representative of four experiments. $\times 200$.

ic plaque $(13,14)$. Therefore, at least in this model, the contribution of other cell types seems to be of minor relevance. Based on these observations, the capability of any given compound to interfere with superantigen-mediated $\mathrm{T}$ cell activation makes it a putative agent to treat at least certain subsets of psoriasis. Indeed, PS-519 interfered with T cell activation. The activation markers analyzed here represent molecules that are expressed during various phases of $\mathrm{T}$ cell activation: CD69 appears very early, CD25 early, and HLA-DR late after in vitro activation.

Besides these phenomenological findings, demonstration of proliferation inhibition and even more interference with adhesive interactions may be of direct functional importance. Lymphocyte migration is an essential requirement for efficient surveillance of tissues for infectious pathogens and for the recruitment of effector cells at sites of inflammation. The extravasation of leukocytes at sites of inflammation is a multiple-step process that involves the interaction of selectins with their carbohydrate ligands, thus mediating the initial tethering of blood leukocytes to the ves-

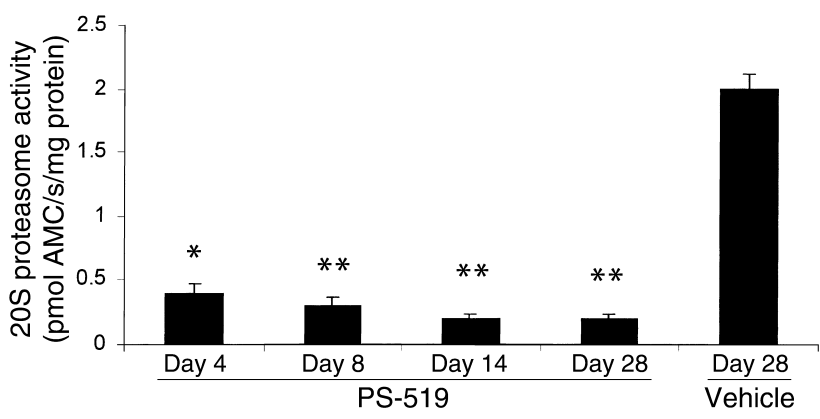

\section{Figure 7}

$20 \mathrm{~S}$ proteasome activity is reduced in PS-519 as compared with vehicle treated mice. Peripheral blood from vehicle- and PS-519-treated mice was drawn 2 hours after the final injection at days $4,8,14$, and 28 . Thereafter, 20 s proteasome activity was determined as described above. PS-519-treated animals showed an $85.7 \% \pm 8.6 \%$ (mean \pm SD) inhibition of the 20 S proteasome activity as compared with vehicle-treated mice at day $28\left({ }^{*} P<0.0001\right)$. Already after 4 days, $81.7 \% \pm 1.6 \%$ inhibition as compared with controls was achieved $\left({ }^{*} P<0.01\right)$. The $20 \mathrm{~S}$ proteasome activity in vehicle-treated mice remained unchanged when measured at 4,8 , and 14 days as compared with day 28 (data not shown). The 20S proteasome activity is given in $\mathrm{pmol} / \mathrm{s} / \mathrm{mg}$ protein. Data represent mean $\pm \mathrm{SD} ; n=6$, days $4-14 ; n=8$, day 28 . 
sel wall $(51,52)$. With respect to the initiation and perpetuation of psoriasis, we and others have recently suggested a role for inappropriate $\mathrm{T}$ cell skin homing based on the upregulation of CLA $(2-4,12,53,54)$. Of note, bacterial superantigens are among the most potent inducers of CLA upregulation (2-4).

Expression of the various $\mathrm{T}$ cell surface markers investigated in this study is under the control of NF- $\mathrm{BB}$ (refs. 25, 41, 45; and M. Podda et al., manuscript submitted for publication). This transcription factor can be activated by a large number of signals, including antigens, cytokines, and infectious agents, in particular bacterial superantigens $(25,45,55,56)$. We therefore investigated the effects of PS-519 on T cell activation-induced NF- $\kappa B$ binding to DNA. That PS-519 exhibits its effects via inhibition of NF- $\mathrm{KB}$ is suggested by our finding of dose-dependent suppression of DNA binding in electrophoretic mobility shift assays. Additionally, in vivo data from PS-519-treated mice showed significant reduction in the activity of its biochemical target, the $20 \mathrm{~S}$ proteasome.

The SCID-hu xenogeneic transplantation model employed in our in vivo studies is a well-established tool for the investigation of various aspects of the pathogenesis of psoriasis as well as for the screening of putative antipsoriatic drugs $(14,48,57,58)$. Using this model, we were able to show normalization of grafts from lesional skin in PS-519-treated mice. The effects were at least equivalent to those obtained with dexamethasone, a drug with known antipsoriatic potential. Given the critical role of NF- $\mathrm{KB}$ in the immune response and other defensive responses, it is noteworthy that the mice treated with PS-519 did not show signs of infection or wasting. Our observations, therefore, clearly are in line with reports from other groups on the beneficial effects of PS-519 in animal models of $\mathrm{T}$ cell-mediated immune disorders (29-31).

The SCID-hu xenogeneic disease model of psoriasis is complex. In this model, several aspects of proteasome inhibition may contribute to the observed beneficial effects: (a) inhibition of $\mathrm{T}$ cell activation within the transplanted psoriatic lesion, since suppression of $T$ cell activation was demonstrated in vitro; (b) inhibition of adhesion molecule expression by $\mathrm{T}$ cells; and (c) inhibition of other cell types such as neutrophils, macrophages, and keratinocytes, since inhibition of the proteasome by PS-519 is not T cell-specific.

In summary, the selective proteasome inhibitor PS-519 is capable of interfering with superantigenmediated $\mathrm{T}$ cell activation, presumably by blocking $\mathrm{NF}-\kappa \mathrm{B}$. Its effectiveness in an animal model for psoriasis suggests its potential as a novel therapeutic regimen in this disease.

\section{Acknowledgments}

We thank Sandra Diehl, Katja Hardt-Weinelt, and Heike Beschmann for excellent technical assistance. T.M. Zollner and M. Podda acknowledge support by August Scheidel-Stiftung, Klein-Stiftung, and Marie Christine
Held und Erika Hecker-Stiftung. W.-H. Boehncke is supported in part by Deutsche Forschungsgemeinschaft grant Bo895/9-1. Part of this work was supported by a grant from Millennium Pharmaceuticals Inc.).

1. Acha-Orbea, H. 1995. Superantigens and tolerance. In T cell receptors. J.I. Bell, M.J. Owen, and E. Simpson, editors. Oxford University Press. Oxford, United Kingdom. 224-265.

2. Leung, D.Y., et al. 1995. Bacterial superantigens induce T cell expression of the skin-selective homing receptor, the cutaneous lymphocyte-associated antigen, via stimulation of interleukin 12 production. J. Exp. Med. 181:747-753

3. Zollner, T.M., Nuber, V., Duijvestijn, A.M., Boehncke, W.H., and Kaufmann, R. 1997. Superantigens but not mitogens are capable of inducing upregulation of E-selectin ligands on human T lymphocytes. Exp. Dermatol. 6:161-166.

4.Zollner, T.M., et al. 1996. The superantigen exfoliative toxin induces cutaneous lymphocyte-associated antigen expression in peripheral human T lymphocytes. Immunol. Lett. 49:111-116.

5. Paliard, X., et al. 1991. Evidence for the effects of a superantigen in rheumatoid arthritis. Science. 253:325-329.

6. Conrad, B., et al. 1994. Evidence for superantigen involvement in insulindependent diabetes mellitus aetiology. Nature. 371:351-355.

7. Henderson, C.A., and Highet, A.S. 1988. Acute psoriasis associated with Lancefield Group C and Group G cutaneous streptococcal infections. Br. J. Dermatol. 118:559-561.

8. Leung, D.Y., et al. 1993. Presence of IgE antibodies to staphylococcal exotoxins on the skin of patients with atopic dermatitis. Evidence for a new group of allergens. J. Clin. Invest. 92:1374-1380.

9. Leung, D.Y., Walsh, P., Giorno, R., and Norris, D.A. 1993. A potential role for superantigens in the pathogenesis of psoriasis. J. Invest. Dermatol. 100:225-228.

10. Valdimarsson, H., Baker, B.S., Jonsdottir, I., Powles, A., and Fry, L. 1995. Psoriasis: a T-cell-mediated autoimmune disease induced by streptococcal superantigens? Immunol. Today. 16:145-149.

11. Nickoloff, B.J., et al. 2000. Is psoriasis a T-cell disease? Exp. Dermatol. 9:359-375.

12. Boehncke, W.H., Dressel, D., Zollner, T.M., and Kaufmann, R. 1996. Pulling the trigger on psoriasis. Nature. 379:777.

13. Wrone-Smith, T., and Nickoloff, B.J. 1996. Dermal injection of immunocytes induces psoriasis. J. Clin. Invest. 98:1878-1887.

14. Nickoloff, B.J., and Wrone-Smith, T. 1999. Injection of pre-psoriatic skin with CD4+ T cells induces psoriasis. Am. J. Pathol. 155:145-158.

15. Marzio, R., Mauel, J., and Betz-Corradin, S. 1999. CD69 and regulation of the immune function. Immunopharmacol. Immunotoxicol. 21:565-582.

16. Ferenczi, K., Burack, L., Pope, M., Krueger, J.G., and Austin, L.M. 2000. CD69, HLA-DR and the IL-2R identify persistently activated $T$ cells in psoriasis vulgaris lesional skin: blood and skin comparisons by flow cytometry. J. Autoimmun. 14:63-78.

17. Davis, R.E., and Smoller, B.R. 1992. T lymphocytes expressing HECA452 epitope are present in cutaneous acute graft-versus-host disease and erythema multiforme, but not in acute graft-versus-host disease in gut organs. Am. J. Pathol. 141:691-698.

18. Paavonen, T., and Renkonen, R. 1992. Selective expression of sialyl-Lewis $x$ and Lewis a epitopes, putative ligands for L-selectin, on peripheral lymph-node high endothelial venules. Am. J. Pathol. 141:1259-1264.

19. Picker, L.J., Michie, S.A., Rott, L.S., and Butcher, E.C. 1990. A unique phenotype of skin-associated lymphocytes in humans. Preferential expression of the HECA-452 epitope by benign and malignant T cells at cutaneous sites. Am. J. Pathol. 136:1053-1068.

20. Beschmann, H.A., Podda, M., Esko, J.D., Kaufmann, R., and Zollner, T.M. 1999. CLA expression can be regulated at the transcriptional level of FucTVII or by inhibition of O-glycosylation using glycoside based primers. J. Invest. Dermatol. 113:446. (Abstr.)

21. Coux, O., Tanaka, K., and Goldberg, A.L. 1996. Structure and functions of the 20S and 26S proteasomes. Annu. Rev. Biochem. 65:801-847.

22. King, R.W., Deshaies, R.J., Peters, J.M., and Kirschner, M.W. 1996. How proteolysis drives the cell cycle. Science. 274:1652-1659.

23. Baumeister, W., Walz, J., Zuhl, F., and Seemuller, E. 1998. The proteasome: paradigm of a self-compartmentalizing protease. Cell. 92:367-380.

24. Chau, V., et al. 1989. A multiubiquitin chain is confined to specific lysine in a targeted short-lived protein. Science. 243:1576-1583.

25. Baeuerle, P.A., and Henkel, T. 1994. Function and activation of NFkappa B in the immune system. Annu. Rev. Immunol. 12:141-179.

26. Regnier, C.H., et al. 1997. Identification and characterization of an IkappaB kinase. Cell. 90:373-383.

27. Read, M.A., et al. 1995. The proteasome pathway is required for cytokineinduced endothelial-leukocyte adhesion molecule expression. Immunity. 2:493-506.

28. Soucy, F., et al. 1999. A novel and efficient synthesis of a highly active 
analogue of clasto-lactacystin $\beta$-lactone. J. Am. Chem. Soc. 121:9967-9976.

29. Elliott, P.J., Pien, C.S., McCormack, T.A., Chapman, I.D., and Adams, J. 1999. Proteasome inhibition: a novel mechanism to combat asthma.J. Allergy Clin. Immunol. 104:294-300.

30. Palombella, V.J., et al. 1998. Role of the proteasome and NF-kappaB in streptococcal cell wall-induced polyarthritis. Proc. Natl. Acad. Sci. USA. 95:15671-15676.

31. Vanderlugt, C.L., Rahbe, S.M., Elliott, P.J., Dal Canto, M.C., and Miller, S.D. 2000. Treatment of established relapsing experimental autoimmune encephalomyelitis with the proteasome inhibitor PS-519. J. Autoimmun. 14:205-211.

32. Scheinman, R.I., Cogswell, P.C., Lofquist, A.K., and Baldwin, A.S., Jr. 1995. Role of transcriptional activation of I kappa B alpha in mediation of immunosuppression by glucocorticoids. Science. 270:283-286.

33. Auphan, N., DiDonato, J.A., Rosette, C., Helmberg, A., and Karin, M. 1995. Immunosuppression by glucocorticoids: inhibition of NF-kappa B activity through induction of I kappa B synthesis. Science. 270:286-290.

34. Scheinman, R.I., Gualberto, A., Jewell, C.M., Cidlowski, J.A., and Baldwin, A.S., Jr. 1995. Characterization of mechanisms involved in transrepression of NF-kappa B by activated glucocorticoid receptors. Mol. Cell. Biol. 15:943-953.

35. Karin, M. 1998. New twists in gene regulation by glucocorticoid receptor: is DNA binding dispensable? Cell. 93:487-490.

36. Korner, M., Rattner, A., Mauxion, F., Sen, R., and Citri, Y. 1989. A brainspecific transcription activator. Neuron. 3:563-572

37. Schmidt, K.N., Podda, M., Packer, L., and Baeuerle, P.A. 1996. Anti-psoriatic drug anthralin activates transcription factor NF-kappa B in murine keratinocytes. J. Immunol. 156:4514-4519.

38. Boehncke, W.H., Sterry, W., Hainzl, A., Scheffold, W., and Kaufmann, R. 1994. Psoriasiform architecture of murine epidermis overlying human psoriatic dermis transplanted onto SCID mice. Arch. Dermatol. Res. 286:325-330.

39. Boehncke, W.H., et al. 2001. Antagonistic effects of the staphylococcal enterotoxin a mutant, SEA(F47A/D227A), on psoriasis in the SCID-hu xenogeneic transplantation model. J. Invest. Dermatol. 116:596-601.

40. Lightcap, E.S., et al. 2000. Proteasome inhibition measurements: clinical application. Clin. Chem. 46:673-683.

41. Podda, M., et al. 1999. Alpha1,3-fucosyltransferase VII mRNA expression is induced by superantigen stimulation and inhibited by $\mathrm{N}$-acetylcysteine. J. Invest. Dermatol. 113:476. (Abstr.)

42. Boehncke, W.H., Zollner, T.M., Dressel, D., and Kaufmann, R. 1997. Induction of psoriasiform inflammation by a bacterial superantigen in the SCID-hu xenogeneic transplantation model. J. Cutan. Pathol. 24:1-7. 43. Leung, D.Y., et al. 1995. Evidence for a streptococcal superantigen-driven process in acute guttate psoriasis. J. Clin. Invest. 96:2106-2112.

44. Lopez-Cabrera, M., et al. 1995. Transcriptional regulation of the gene encoding the human C-type lectin leukocyte receptor AIM/CD69 and functional characterization of its tumor necrosis factor-alpha-responsive elements. J. Biol. Chem. 270:21545-21551.

45. Barnes, P.J., and Karin, M. 1997. Nuclear factor-kappaB: a pivotal transcription factor in chronic inflammatory diseases. N. Engl. J. Med. 336:1066-1071.

46. Strickland, I., Hauk, P.J., Trumble, A.E., Picker, L.J., and Leung, D.Y. 1999. Evidence for superantigen involvement in skin homing of T cells in atopic dermatitis. J. Invest. Dermatol. 112:249-253.

47. Boehncke, W.H. 1999. The SCID-hu xenogeneic transplantation model: complex but telling. Arch. Dermatol. Res. 291:367-373.

48. Dam, T.N., Kang, S., Nickoloff, B.J., and Voorhees, J.J. 1999. 1Alpha,25dihydroxycholecalciferol and cyclosporine suppress induction and promote resolution of psoriasis in human skin grafts transplanted on to SCID mice. J. Invest. Dermatol. 113:1082-1089.

49. Christophers, E. 1996. The immunopathology of psoriasis. Int. Arch. Allergy Immunol. 110:199-206.

50. Gottlieb, S.L., et al. 1995. Response of psoriasis to a lymphocyte-selective toxin (DAB389IL-2) suggests a primary immune, but not keratinocyte, pathogenic basis. Nat. Med. 1:442-447.

51. Springer, T.A. 1994. Traffic signals for lymphocyte recirculation and leukocyte emigration: the multistep paradigm. Cell. 76:301-314.

52. von Andrian, U.H., and Mackay, C.R. 2000. T-cell function and migration. Two sides of the same coin. N. Engl. J. Med. 343:1020-1034.

53. Boehncke, W.H. 1996. Psoriasis and bacterial superantigens: formal or causal correlation? Trends Microbiol. 4:485-489.

54. Robert, C., and Kupper, T.S. 1999. Inflammatory skin diseases, T cells, and immune surveillance. N. Engl.J. Med. 341:1817-1828.

55. Trede, N.S., Castigli, E., Geha, R.S., and Chatila, T. 1993. Microbial superantigens induce NF-kappa B in the human monocytic cell line THP-1.J. Immunol. 150:5604-5613.

56. Trede, N.S., Tsytsykova, A.V., Chatila, T., Goldfeld, A.E., and Geha, R.S. 1995. Transcriptional activation of the human TNF-alpha promoter by superantigen in human monocytic cells: role of NF-kappa B. J. Immunol. 155:902-908.

57. Schon, M.P. 1999. Animal models of psoriasis: what can we learn from them? J. Invest. Dermatol. 112:405-410.

58. Boehncke, W.H., Kock, M., Hardt-Weinelt, K., Wolter, M., and Kaufmann, R. 1999. The SCID-hu xenogeneic transplantation model allows screening of anti-psoriatic drugs. Arch. Dermatol. Res. 291:104-106. 